\title{
Finite Element Analysis and Experiment of the Bruise Behavior of Carrot under Impact Loading
}

\author{
Xudong Xia ${ }^{1,2}$, Zhanhong Xu ${ }^{1}$, Chennan Yu ${ }^{1}$, Qiaojun Zhou ${ }^{1}$ and Jianneng Chen ${ }^{1,2, *(1)}$ \\ 1 Faculty of Mechanical Engineering \& Automation, Zhejiang Sci-Tech University, Hangzhou 310018, China; \\ xiaxudong@zstu.edu.cn (X.X.); 2018g0505053@mails.zstu.edu.cn (Z.X.); \\ 201910501021@mails.zstu.edu.cn (C.Y.); zqj@cjlu.edu.cn (Q.Z.) \\ 2 Key Laboratory of Transplanting Equipment and Technology of Zhejiang Province, Hangzhou 310018, China \\ * Correspondence: jiannengchen@zstu.edu.cn; Tel.: +86-130-6570-1536
}

Citation: Xia, X.; Xu, Z.; Yu, C.; Zhou, Q.; Chen, J. Finite Element Analysis and Experiment of the Bruise Behavior of Carrot under Impact Loading. Agriculture 2021, 11, 471 https://doi.org/10.3390/agriculture 11060471

Academic Editor: Dimitrios S. Paraforos

Received: 15 April 2021

Accepted: 17 May 2021

Published: 21 May 2021

Publisher's Note: MDPI stays neutral with regard to jurisdictional claims in published maps and institutional affiliations.

Copyright: (c) 2021 by the authors. Licensee MDPI, Basel, Switzerland. This article is an open access article distributed under the terms and conditions of the Creative Commons Attribution (CC BY) license (https:// creativecommons.org/licenses/by/ $4.0 /)$.

\begin{abstract}
Root-stem separating is one of the most important processes in carrot harvesting, but it is easy to cause damage due to the impact. In order to reduce the damage of carrot harvesting and provide the basis for the design of the separation mechanism, the damage mechanism of carrot was studied by the finite element method (FEM) and pendulum experiment in this study. Through the simulation analysis and the pendulum experiment, it was found that the critical damage impact force was $45.2 \mathrm{~N}$ and $43.1 \mathrm{~N}$, respectively. Comparing the two results, the critical impact force of the carrot was basically the same, with an error of $4.87 \%$. In conclusion, the FEM was reliable for the carrot damage prediction, and the critical impact force could be used for the design of a carrot harvesting mechanism.
\end{abstract}

Keywords: carrot; root-stem separation; bruise; FEM; experiment

\section{Introduction}

The carrot is one of the top ten vegetables in the world, and its planting area is widely distributed around the world. However, the mechanization degree of the carrot in the harvest stage is not high, and further research is needed [1,2]. The carrot harvest includes carrot pulling, transportation, root-stem separation, etc. The root-stem separation is the most important process in the harvest process, and its separation effect directly affects the damage rate and consistency rate of carrots [3,4]. The pulling harvest is one of the main ways to harvest the carrot. Moreover, the root-stem separation stage is mainly through the impact between the carrot and the pull rod to separate the carrot at the root-stem junction $[5,6]$. However, the carrot is easy to damage due to the impact, and the degree of damage depends on the structural parameters and working parameters of the root-stem separation device. There is no research on the damage mechanism of the carrot pulling harvest in the literature, so the structural parameters and working parameters of the separation device are based on experience and a lack of theoretical basis.

The material characteristics of carrots from different areas, varieties and growth periods are different. Even with the same root-stem separation device and working parameters, the damage degree is different. So the work parameters of the separation device need to be adjusted for different batches of the carrot. However, it is unrealistic to obtain the working parameters through a physical test every time, which takes a long time. Therefore, this study intends to establish a reliable simulation model to facilitate the damage analysis of different batches of carrots and obtain the best working parameters, so as to provide a basis for the adjustment of the working parameters of the carrot root-stem separation device.

It is difficult to measure and describe the internal stress change caused by the impact during the harvest of agricultural products only through experiments. Therefore, the finite element analysis (FEA) method is widely used in the dynamic response of agricultural 
products, and is often used to predict and simulate nonlinear behaviors such as the internal stress and deformation of the fruit impact. Ji simulated the manipulator picking apples by FEM, and analyzed the influence of different mechanical finger types on the dynamic response of apples [7]. Kabas combined the FEM method and experiment to explore the deformation behavior of tomatoes under impact load [8]. Celik used FEM to simulate apple drop, and used a high-speed camera to verify the deformation behavior consistent with the simulation [9]. Salarikia simulated the drop of pears at two different drop angles and four different impact surfaces by FEM, and explored the internal stress-strain distribution [10]. Miraei used FEM to predict the damage of grapefruit under external load [11]. These literatures simplified the constitutive model of agricultural products into a linear elastic model or elastic-plastic model, but in real life, agricultural products exhibited visco-elastic properties when subjected to an external impact load. Kim endowed apple with viscoelastic properties, and explored the mechanical behavior of apple under different impact loads by FEM [12]. Gao regarded potato as a visco-elastic body, and analyzed its drop response by FEM, and verified it by experiment [13]. However, different tissues of fruits have different material properties, and it is an effective way to improve the simulation accuracy to establish a finite element model based on the actual growth characteristics of fruits. Therefore, this study intends to establish a finite element model of visco-elastic multi-layer tissues according to the actual growth characteristics of carrots, and verify the reliability of the model by the pendulum impact test.

In this study, the elastic-plastic material properties and visco-elastic material properties of carrots were obtained by the compression test and relaxation test, and a 3D model of carrots with core, flesh and stem was established. Based on the explicit dynamic of FEM, the impact condition between the carrot and pull rod was simulated, and the internal stress and the critical impact force of the carrots were analyzed. Finally, the impact test was carried out by a self-made pendulum device, and the results were compared and analyzed with the finite element simulation results.

\section{Materials and Method}

\subsection{Materials}

The carrot used in the experiment was 'New Red Carrot' selected from Zhejiang, China, and it was necessary to ensure that it has no deformities, no cracks and no damage. As shown in Figure 1, carrots consist of two parts, the core and the flesh, separated by a clear dividing line. For follow-up experiments, both the core and the flesh need to be made into cylindrical samples (Figure 2). Firstly, a sampler with an inner diameter of $10 \mathrm{~mm}$ was used to drill the cylindrical sample along the diameter of the carrots. Then the drilled cylindrical sample was fixed on a special device, and cut at both ends in parallel. Samples of the two parts were taken on both sides of the dividing line, the size was $\varphi 10 \mathrm{~mm} \times 10 \mathrm{~mm}$.

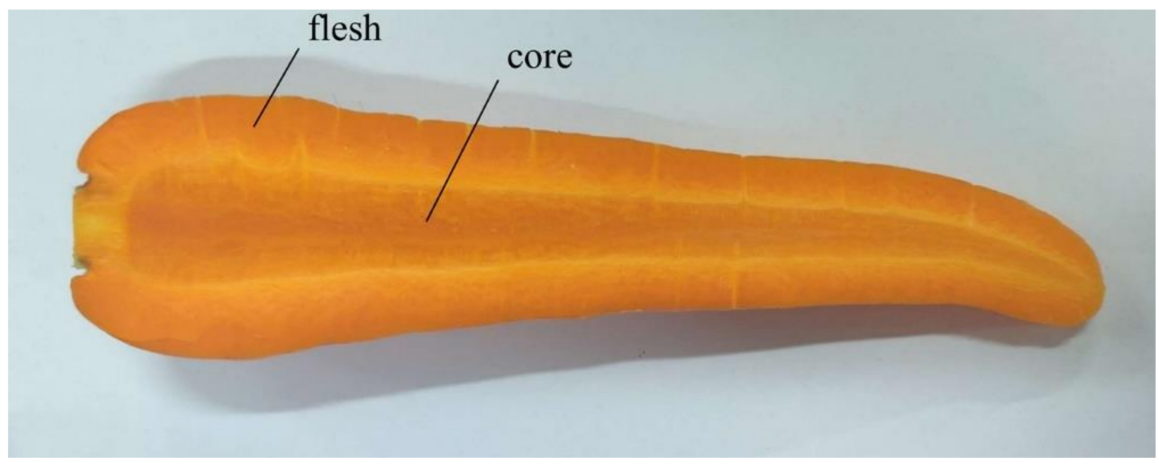

Figure 1. The longitudinal profile of carrot samples. 


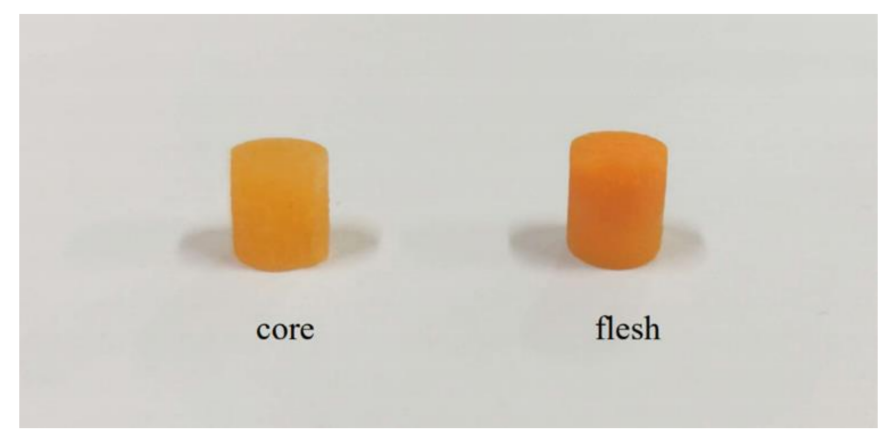

Figure 2. Cylinder samples of the carrot.

\subsection{Mechanical Properties}

Carrot is a visco-elastic material. Its elastic behavior is unrelated to the loading speed, representing the recoverable deformation, and its viscosity behavior is related to the loading speed, representing the decay deformation. The two material characteristic parameters of the carrot are measured and calculated by the compression test and stress relaxation test, respectively, in this study.

\subsubsection{Compression Test}

In order to determine the physical deformation characteristics and elastic material properties such as elastic modulus, Poisson's ratio and bio-yield point of carrot, compression tests were carried out on the carrot samples. The test was carried out by an electronic universal material testing machine (LDW-1) at room conditions $\left(22^{\circ} \mathrm{C} \pm 1{ }^{\circ} \mathrm{C}, 40-60 \% \mathrm{RH}\right)$. The flesh samples of the carrot were compressed between two hard metal plates until a certain deformation was achieved, as shown in Figure 3. According to ASAE food material standards, the test used $2.5 \mathrm{~mm} / \mathrm{min}$ compression rate, each test with 10 samples [14].

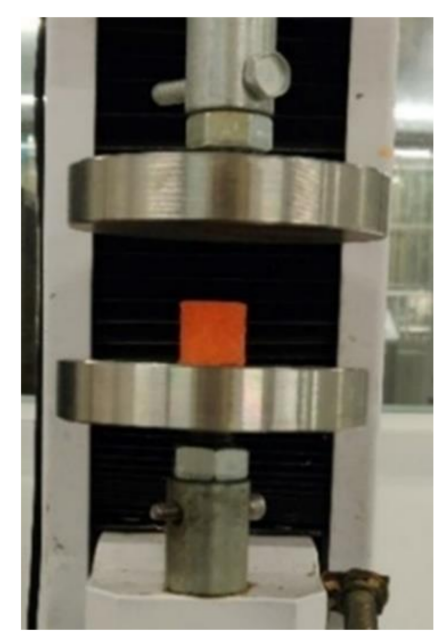

Figure 3. Compression test.

The stress-strain curve of the carrot flesh was obtained by the compression test, as shown in Figure 4. The elastic deformation of the sample occurred at the beginning of compression, and the curve showed a linear relation. When the curve reached the bio-yield point, the sample began to undergo plastic deformation, which was irreversible. When the curve reached the failure point, the sample broke and the stress began to decrease. It could also be obtained from the figure that bio-yield stress is the stress of the bio-yield point, elastic modulus is the tangent of the elastic zone, and the tangent modulus is the slope of the connection between the bio-yield point and the failure point. 


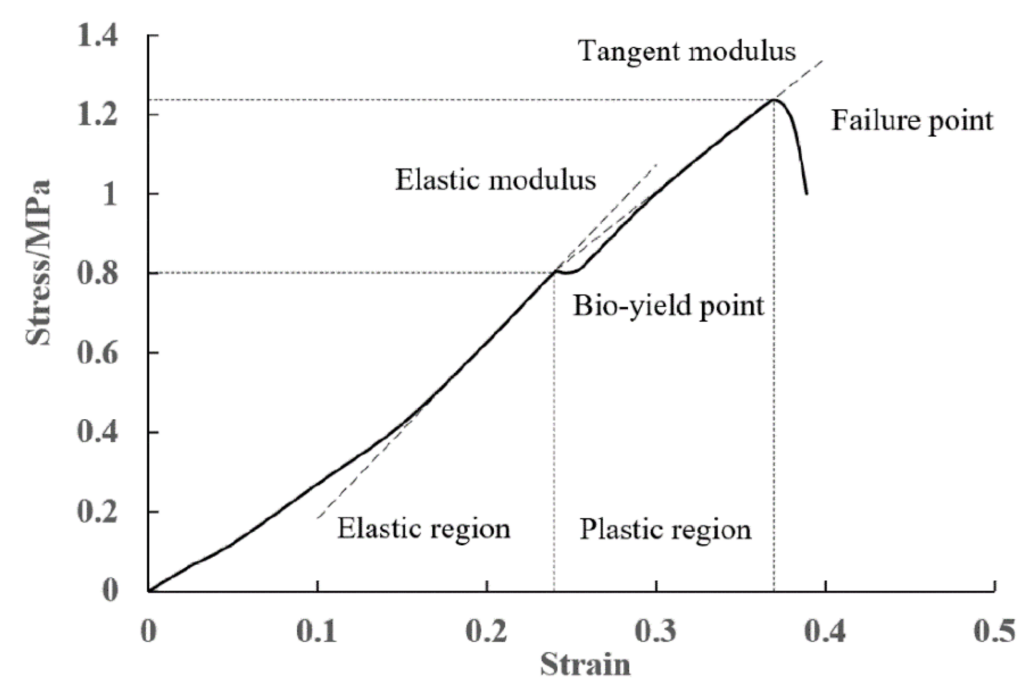

Figure 4. The stress-strain curve of carrot flesh.

According to Equation (1), Poisson 's ratio was calculated by measuring the diameter variation and compression deformation of cylinder samples [15].

$$
\mu=\frac{\varepsilon_{0}}{\varepsilon_{1}}=\frac{\Delta L / L_{0}}{\Delta D / D_{0}}
$$

where $L_{0}$ is the initial length before compression, $\Delta L$ is the length deformation after compression, $D_{0}$ is the initial radius before compression, and $\Delta D$ is the diameter deformation after compression.

In the elastic stage of the carrot sample, the diameter deformation was measured by a vernier caliper with a resolution of $0.02 \mathrm{~mm}$, and the length deformation was obtained by the sensor of the universal material testing machine.

Similarly, a compression test of the carrot core was carried out, and the elastic-plastic parameters of the carrot were measured and calculated, as shown in Table 1.

Table 1. Average value of carrot elastic-plastic material parameters.

\begin{tabular}{ccccc}
\hline Materials & $\begin{array}{c}\text { Elastic Modulus } \\
\mathbf{( M P a )}\end{array}$ & $\begin{array}{c}\text { Bio-Yield Stress } \\
\mathbf{( M P a}\end{array}$ & $\begin{array}{c}\text { Tangent } \\
\text { Modulus (MPa) }\end{array}$ & Poisson's Ratio \\
\hline Flesh & 4.45 & 0.806 & 3.35 & 0.477 \\
Core & 4.63 & 0.821 & 3.42 & 0.479 \\
\hline
\end{tabular}

\subsubsection{Stress Relaxation Test}

To describe the visco-elastic behavior of carrot, the time-domain elastic modulus was obtained by the stress relaxation test. The stress relaxation test was to compress the sample to a certain amount of deformation in a very short time and keep the deformation constant, and the stress would continue to decrease to residual stress [16].

The optimum conditions of the test were obtained by the three-factor and three-level orthogonal test. The test was carried out by an electronic universal material testing machine (LDW-1) at room conditions $\left(22^{\circ} \mathrm{C} \pm 1{ }^{\circ} \mathrm{C}, 40-60 \% \mathrm{RH}\right)$. The flesh samples of the carrot were placed between two hard metal plates and compressed at a compression rate of $1.5 \mathrm{~mm} / \mathrm{s}$. Moreover, when the compression deformation reached $1.5 \mathrm{~mm}$, the metal plates remained for $120 \mathrm{~s}$. The obtained stress relaxation curve is shown in Figure 5. 


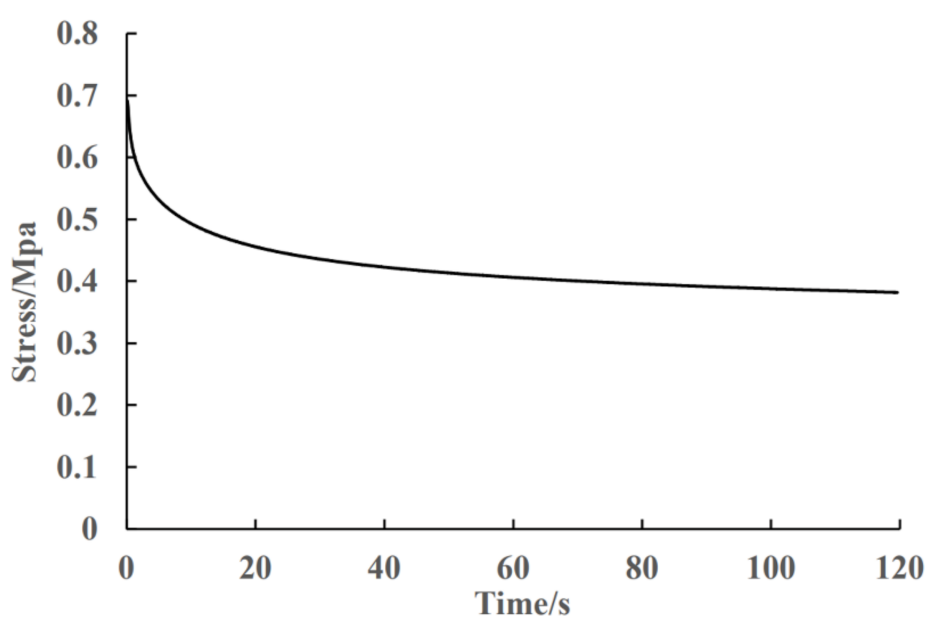

Figure 5. The stress relaxation curve of carrot flesh.

In order to solve the stress relaxation phenomenon of complex materials, this study selected five elements of generalized Maxwell model to fit the stress relaxation curve. The model consists of two different Maxwell models and a spring in parallel [17]. The constitutive model of the model is shown in Equation (2), as follows:

$$
E_{t}=E_{1} e^{-t / T_{1}}+E_{2} e^{-t / T_{2}}+E_{\infty}
$$

where $E_{1}$ and $E_{2}$ are the decay elastic modulus, $E_{\infty}$ is the equilibrium elastic modulus, $T_{1}$ and $T_{2}$ is the relaxation time.

The stress relaxation curve of the carrot flesh was analyzed by nonlinear regression analysis by SPSS software. The fitting coefficient $R^{2}$ is 0.998 , and the fitting equation of carrot flesh obtained can be expressed as Equation (3).

$$
E_{t}=0.727 e^{-t / 1.684}+0.775 e^{-t / 26.31}+1.831
$$

In ABAQUS finite element software, Prony series is usually used to describe the viscoelasticity of materials [18], which can be obtained by the conversion of Maxwell model parameters. The expression is as follows:

$$
\begin{gathered}
\bar{g}_{i}^{p}=\frac{E_{i}}{E_{0}} \\
\bar{\tau}_{i}^{p}=T_{i} \\
E_{0}=E(t=0)=E_{\infty}+\sum_{i=1}^{n} E_{i}
\end{gathered}
$$

where $\bar{g}_{i}^{p}$ is the relative elastic modulus and $\bar{\tau}_{i}^{p}$ is the relaxation time.

Similarly, the stress relaxation test of the carrot core was carried out, and the viscoelastic parameters were measured and fitted, as shown in Table 2.

Table 2. The visco-elastic material parameters of carrot for FEA.

\begin{tabular}{ccccc}
\hline Materials & $\begin{array}{c}\text { Relative Elastic } \\
\text { Modulus } \bar{g}_{\mathbf{1}}^{p}\end{array}$ & $\begin{array}{c}\text { Relative Elastic } \\
\text { Modulus } \bar{g}_{\mathbf{2}}^{p}\end{array}$ & $\begin{array}{c}\text { Relaxation } \\
\text { Time } \overline{\boldsymbol{\tau}}_{\mathbf{1}}^{p}(\mathbf{s})\end{array}$ & $\begin{array}{c}\text { Relaxation } \\
\text { Time } \overline{\boldsymbol{\tau}}_{\mathbf{2}}^{p}(\mathbf{s})\end{array}$ \\
\hline Flesh & 0.218 & 0.233 & 1.684 & 26.31 \\
Core & 0.238 & 0.237 & 1.623 & 30.3 \\
\hline
\end{tabular}




\subsection{FEM of Carrot Impact Damage}

In order to explore the damage problem in the process of root-stem separation of carrot, this study intends to establish an impact model between the carrot and pull rod, and to obtain a reliable model through experimental verification or correction. It is obtained how much load on the carrot will cause damage, which provides a basis for the design of the separation device.

\subsubsection{Establishment of 3D Solid Model}

Based on the actual appearance of carrots, a multi-layer model of carrot core and flesh was established, and the stems were connected at the root-stem junction. The geometric sizes of the carrot model were measured by slide gauge and averaged. The original model of the pull rod is complex, but in actual working conditions, the impact is not related to the structure in the length direction, and only related to the shape and size of the cross section. Therefore, considering the diameter size of the actual pull rod, the pull rod is simplified into a cylindrical rod with a diameter of $16 \mathrm{~mm}$. The solid models of the carrot and pull rod were established by SolidWorks, and the two were assembled. Since the movement of the two before the impact is meaningless, in order to reduce the calculation time, the initial position of the carrot is closely attached to the pull rod, as shown in Figure 6a.

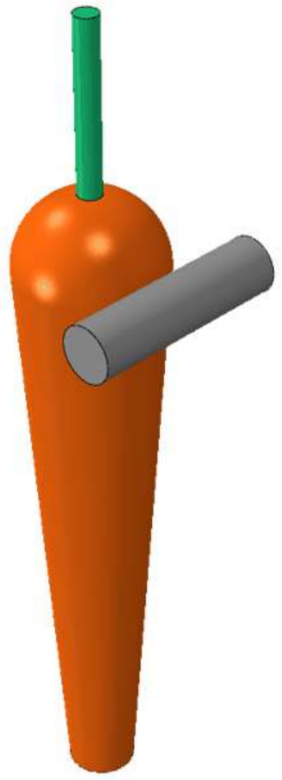

(a) 3D model

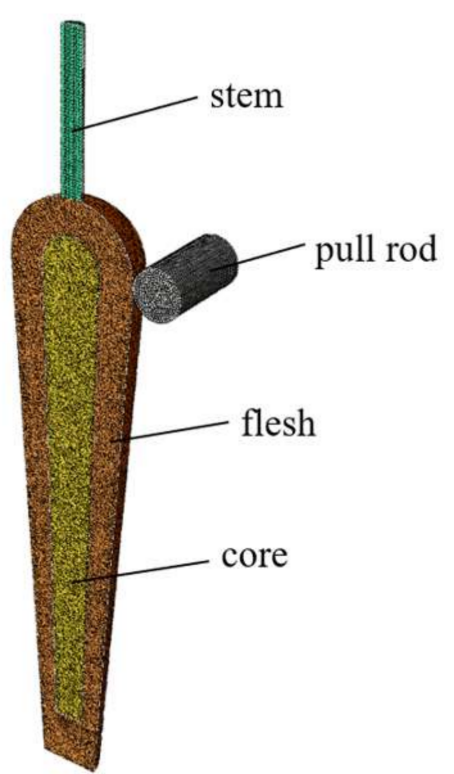

(b) meshed model

Figure 6. Impact simulation using FEA.

\subsubsection{Establishment of Finite Element Model}

The assembly drawings established by SolidWorks were imported into ABAQUS software. The models of carrot flesh, core, stem and pull rod were all used as 3D solid elements. In this study, the core and flesh were endowed with two different material properties, and both were assumed to be isotropic materials. The specific material parameters are shown in Tables 1 and 2 in Section 2.2. Since the yield strength of the pull rod is far greater than that of carrot, the pull rod can be set as a rigid body to reduce the simulation calculation time.

Usually in the simulation of fruits and vegetables, tetrahedral elements and hexahedral elements are used, which have good adaptability to irregular shapes. Therefore, the core and flesh of the carrot were divided by tetrahedral elements, and the pull rod and stem were divided by hexahedral elements, as shown in Figure $6 \mathrm{~b}$. After the meshing was completed, the contact conditions and constraints between the carrot and pull rod were set as follows: The impact contact between the carrot and pull rod was defined as the 
surface-to-surface contact, and the contact properties were set. The core and flesh of the carrot were connected into a whole by surface-to-surface tie constraints. The bottom of the stem and the top of the flesh were connected by surface-to-surface tie constraints.

As the impact surface, the centroid reference point position of the pull rod was fixed. A fixed constraint was applied to the top of the stem to simulate the carrot being clamped, and the initial velocity was applied to the carrot. A probe was added at the centroid reference position of the pull rod to read the impact force of the carrot on the pull rod. In FEA, the most important purpose is to find out the maximum stress and impact force, and the bruise usually occurs first in the maximum stress position.

\subsection{Experimental Design}

The drop experiment is a common way to study the influencing factors of the impact damage on fruits. However, the physical properties of different parts are quite different. Moreover, it is difficult to control the impact position of long-strip fruits such as carrots in the drop experiment. Therefore, a pendulum device was designed for carrot impact damage analysis [19], as shown in Figure 7.

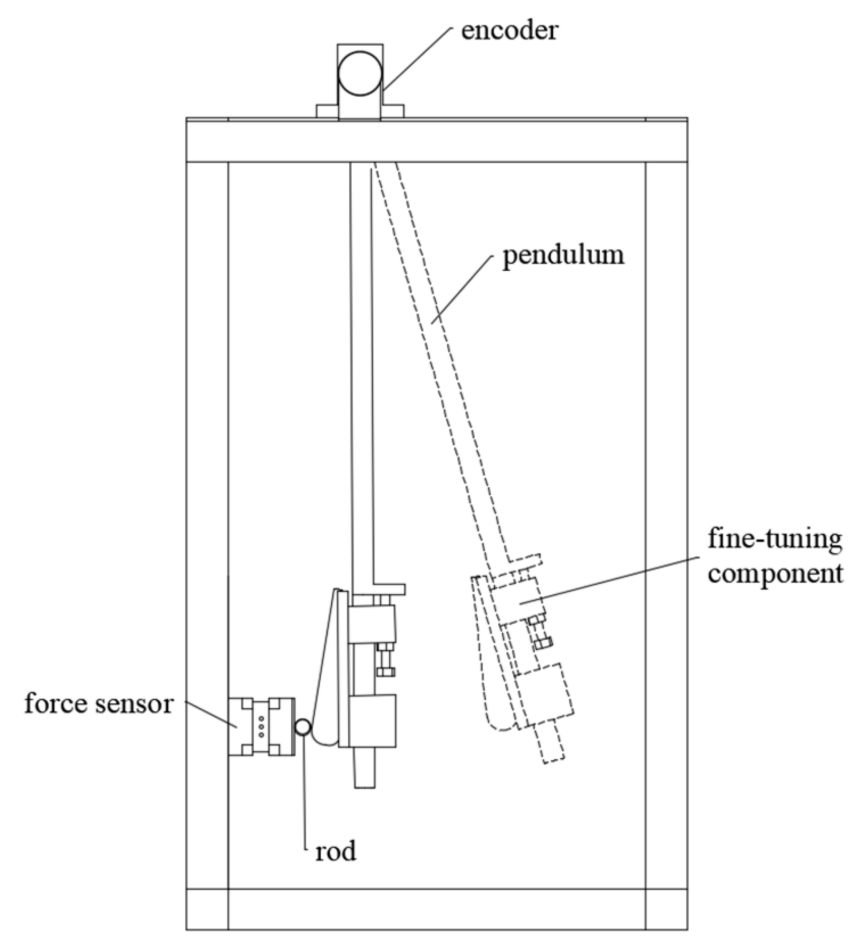

Figure 7. The pendulum device.

The pendulum device mainly includes the encoder (E6B2-CWZ6C), pendulum, finetuning component and impact component. The encoder is used to record the initial angle of the pendulum and the change process of the angle. The fine-tuning component is used to fine tune the impact position of the carrot and the impact part to improve the test accuracy. The impact component is composed of a force sensor (Cl-YD-3301) and a steel rod used to simulate the pull rod with a diameter of $16 \mathrm{~mm}$.

In order to explore the relationship between impact force and carrot damage, the critical impact force is predicted by the fitting curve of impact force and carrot damage rate. The 'New Red Carrot' from Zhejiang, China, was selected for the experiment. Before the experiment, 300 carrots were randomly divided into 10 groups, and the mass of each carrot was measured. The experiment selected 10 groups of initial potential energies in a wide range, and to ensure that the initial potential energies of the carrots in the groups were the same, the initial swing angle was calculated from the mass of each carrot. After adjusting the swing angle and releasing freely, the carrot impacted with the steel rod. After 
the pendulum has bounced back, it would be fixed to prevent the second impact of the carrot. The above steps were repeated until all experiments were completed, and the data were recorded and processed. According to the impact force measured by the experiment, the appropriate impact force interval was selected, and the carrots were reclassified into several groups.

The carrot samples after the experiment were stored at room conditions $\left(22 \pm 1{ }^{\circ} \mathrm{C}\right.$, $40-60 \% \mathrm{RH}$ ) for $24 \mathrm{~h}$ to detect the damage of the carrots. The impact site was judged whether there was a slight discoloration or crack, and verified whether it had softened, as shown in Figure 8.

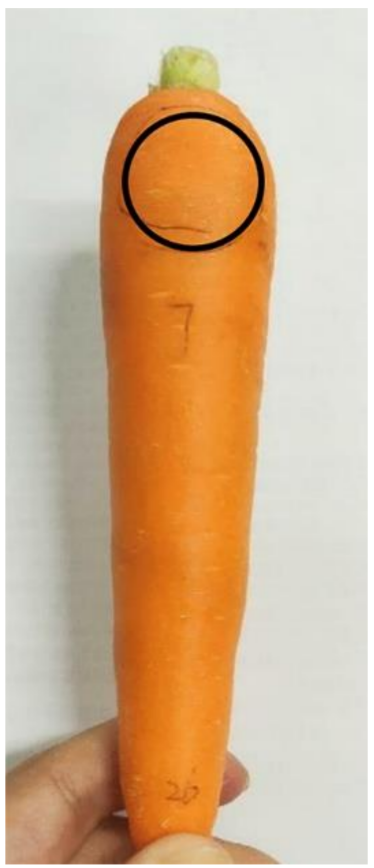

(a) No damage

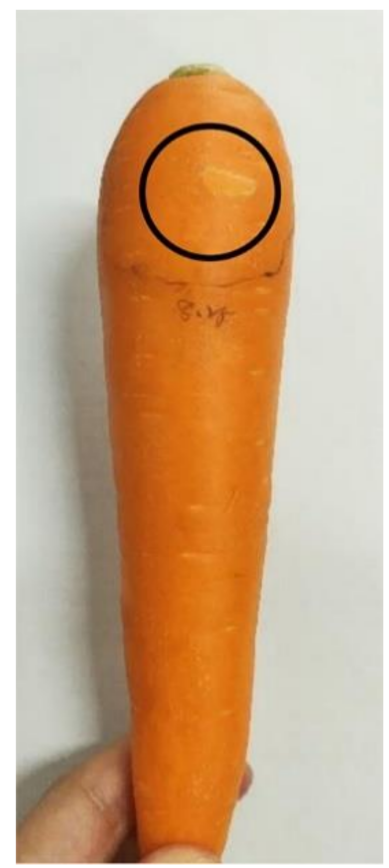

(b) Obvious damage

Figure 8. Damage status of carrot.

\section{Results}

\subsection{Results of FEA}

After pre-processing and simulation, effective data and visualization results were obtained at post-processing. The impact simulation is shown in Figure 9, the impact between the carrot and pull rod began from $0 \mathrm{~ms}$, and the stress at the impact site increased gradually until it reached the peak value at $2 \mathrm{~ms}$. After this, the upper part of the carrot began to rebound due to the reaction force of the pull rod, and the stress at the impact site gradually decreased. At the same time, the carrot began to tilt due to the inertia of the lower part of the carrot. The carrot vibrated due to the local impact, with slight stress in the middle part, starting from $4 \mathrm{~ms}$. Moreover, due to the continued rebound of the carrot and the restriction of the stem, obvious stress appeared at the junction of the stem.

In this study, the von Mises failure criterion, commonly used to estimate the yield performance of materials, was used to analyze the equivalent stress of the carrot [20]. In other words, the region where the equivalent stress exceeded the bio-yield stress was judged as bruised. It could be seen from the simulation result that the equivalent stress of the flesh was far greater than that of the core, so only the damage of the flesh needed to be considered. The maximum equivalent stress occurred at the near surface, which indicated that carrot is likely to damage at the near surface first. 


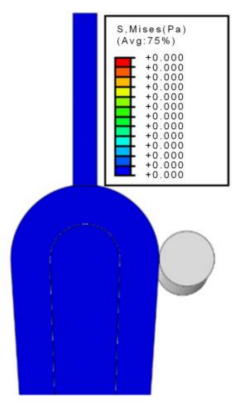

$\mathrm{T}=0 \mathrm{~ms}$

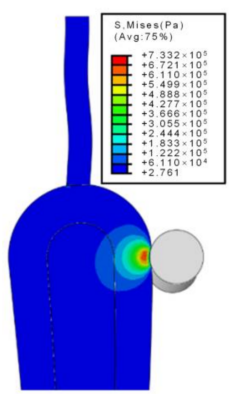

$\mathrm{T}=3 \mathrm{~ms}$

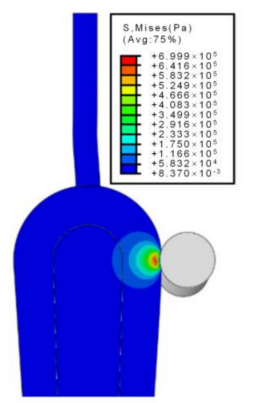

$\mathrm{T}=1 \mathrm{~ms}$

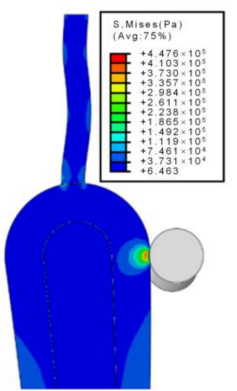

$\mathrm{T}=4 \mathrm{~ms}$

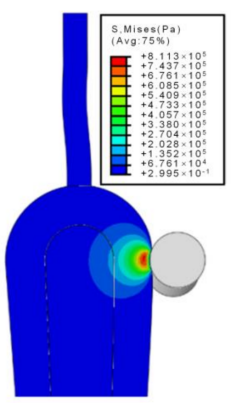

$\mathrm{T}=2 \mathrm{~ms}$

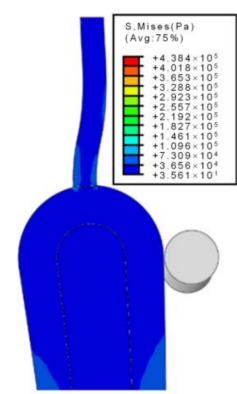

$\mathrm{T}=5 \mathrm{~ms}$

Figure 9. Simulation results of impact.

The curves of the maximum equivalent stress and impact force of the carrot with time are shown in Figure 10. During the impact process, the impact force and the maximum equivalent stress of the carrot reached the maximum at $2 \mathrm{~ms}$. During the rebound process, the impact force gradually decreased to zero, and the maximum equivalent stress still had $0.05 \mathrm{MPa}$ residual stress in the non-contact state. This is probably due to the non-uniform plastic deformation of the carrot [21].

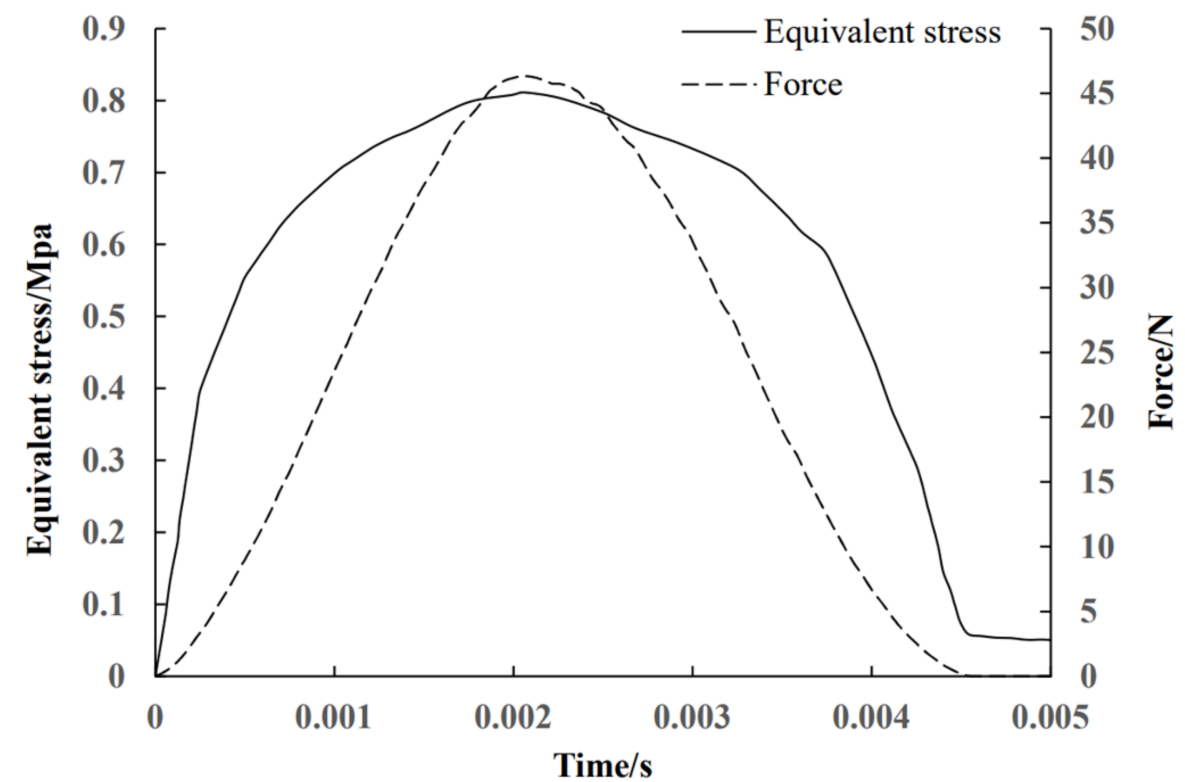

Figure 10. Curves of equivalent stress and impact force changing with time.

According to Table 1 in Section 2.2, the bio-yield stress of the flesh was $0.806 \mathrm{MPa}$. Figure 8 shows that the maximum equivalent stress increased from $0 \mathrm{MPa}$ at $0 \mathrm{~ms}$ to $0.806 \mathrm{MPa}$ at $1.9 \mathrm{~ms}$, and the carrot had elastic deformation without damage. From $1.9 \mathrm{~ms}$, a region where the maximum equivalent stress of carrot is greater than its bio-yield stress 
was identified as having undergone plastic permanent deformation and as being damaged, with the impact force of $45.2 \mathrm{~N}$. At the same time, since the position of the maximum equivalent stress was not fixed, new regions of the carrot were constantly identified as bruised from $1.9 \mathrm{~ms}$ to $2.2 \mathrm{~ms}$. After $2.2 \mathrm{~ms}$, the maximum equivalent stress of the carrot began to decrease from $0.806 \mathrm{MPa}$, and the damaged region was no longer increased. Therefore, through the impact simulation, it can be concluded that the critical impact force between the carrot and the pull rod with a diameter of $16 \mathrm{~mm}$ is $45.2 \mathrm{~N}$.

Energy check is a method to verify the accuracy of finite element simulation. The dynamic simulation energy activity of carrot impact is shown in Figure 11. During the impact between the carrot and the pull rod, its kinetic energy was gradually transformed into internal energy, which was absorbed by the carrot. It could be noticed that at $1.9 \mathrm{~ms}$, the model began to show plastic strain energy, at which time the carrots began to appear damaged. The total energy of the entire impact process was checked, and it was found that the fluctuation was less than $5 \%$, and it could be considered that the total energy remained basically unchanged. Hourglassing is a kind of deformation that does not produce strain change in finite element simulation. Under normal circumstances, the hourglass energy should not exceed $5 \%$ of the internal energy, so it can be said that the accuracy of the FEM-based simulation in terms of energy is reliable.

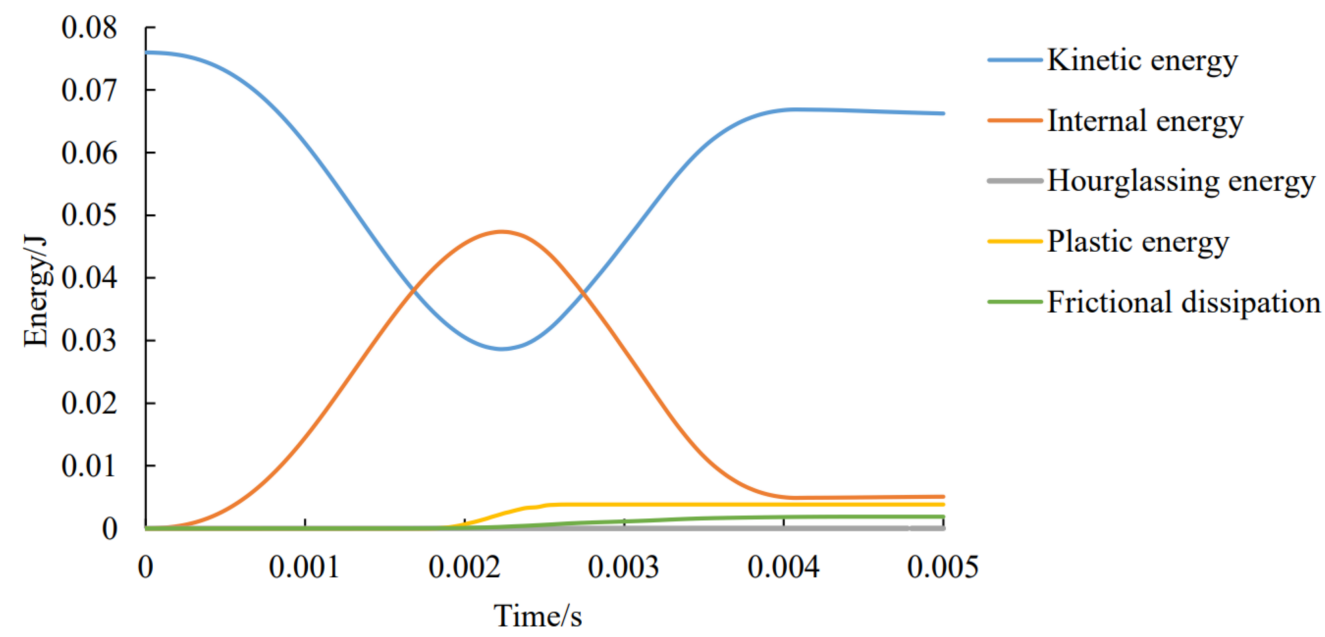

Figure 11. Energy analysis in FEM-based simulation.

\subsection{Results and Analysis of Experiment}

In order to explore the relationship between impact force and carrot damage, and predict the critical impact force, the fruit quality was evaluated by defining the fruit damage rate, as shown in Equation (7).

$$
P=\frac{N_{b}}{N} \times 100 \%
$$

where $P$ is the fruit damage rate, $N_{b}$ is the number of damaged fruits in each group and $N$ is the total number of fruits in each group.

The carrots have been regrouped according to the impact force, the carrot damage rate of each group was calculated, and the damage rate was assigned to the average number of impact forces in the group.

Logarithmic regression analysis was carried out on the experimental data, and the relationship between the damage rate and the impact force is shown in Figure 12. The determination coefficient $R^{2}$ is 0.9275 , and the fitting equation is $P=0.76 \ln (F)-2.86$. When the impact force between the carrot and steel rod is less than $43.1 \mathrm{~N}$, no damage was observed on the carrot. When it was higher than $43.1 \mathrm{~N}$, the damage rate of the carrots increased rapidly, from $0 \%$ at $43.1 \mathrm{~N}$ to $50 \%$ at $83 \mathrm{~N}$, and then to $64 \%$ at $100 \mathrm{~N}$. The impact force of the carrot increased with the increase in the maximum contact stress. When the 
maximum contact stress was greater than the bio-yield stress, the carrot was damaged. Meanwhile, the damage rate of the carrot increased with the impact force.

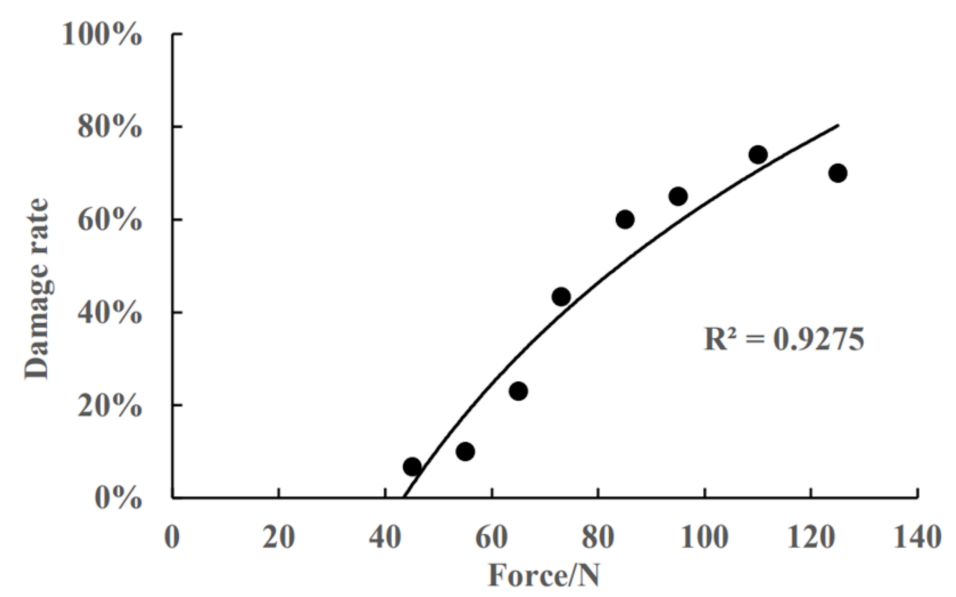

Figure 12. Relationship between fruit damage rate and impact force.

\section{Discussion}

In the experiment, the critical impact force between the 'New Red Carrot' and the steel rod with a diameter of $16 \mathrm{~mm}$ predicted was $43.1 \mathrm{~N}$, and in FEA, the critical impact force was $45.2 \mathrm{~N}$. Thus, in the process of predicting the critical impact force, the error between the simulation results and experimental results was only $4.87 \%$. Therefore, it showed that the result of the FEM-based simulation was reliable.

After that, more in-depth mechanism studies can be carried out. The damage factors of the carrot and pull rod can be analyzed, and the measures to reduce the damage can be put forward. The critical impact velocity between the carrot and pull rod can be calculated by the finite element model. Through kinematic analysis and dynamic analysis, the relationship between the speed of the pull rod and carrot damage can be established, so as to complete the structural optimization and working parameters optimization of root-stem separation.

Author Contributions: Conceptualization, X.X. and J.C.; methodology, Z.X., C.Y. and Q.Z.; investigation, X.X. and Z.X.; data curation, C.Y. and Q.Z.; formal analysis, X.X. and J.C.; writing-original draft, Z.X.; writing-review and editing, X.X., C.Y., Q.Z. and J.C.; project administration, X.X.; funding acquisition, X.X. All authors have read and agreed to the published version of the manuscript.

Funding: This research was funded by the National Natural Science Foundation of China (Grant No. 51805487) and Basic Public Welfare Research Projects of Zhejiang Province (Grant No. LGN19E050003).

Institutional Review Board Statement: Not applicable.

Informed Consent Statement: Not applicable.

Data Availability Statement: The data presented in this study are available on request from the corresponding author.

Acknowledgments: The author would like to thank the Key Laboratory of Transplanting Equipment and Technology of Zhejiang Province for its support. The authors also thank Bin Yuan, Tianlong Chen, Libin Guo and Yi su, for their help.

Conflicts of Interest: The authors declare no conflict of interest.

\section{References}

1. Wang, J.; Du, D. Vegetable mechanized harvesting technology and its development. Trans. Chin. Soc. Agric. Mach. 2014, 45, 81-87.

2. Li, K.; Yang, B. Planting status and research progress on seeding machine of carrot at home and abroad. Agric. Eng. 2015, 5, 1-5.

3. Leszczynski, N. The influence of working parameters of a carrot harvester on carrot root danage. Maint. Reliab. 2011, 49, 35-41. 
4. Wang, J.; Shang, S. Development and experiment of double-row self-propelled carrots combine. Trans. Chin. Soc. Agric. Mach. 2012, 28, 38-43.

5. Zeng, G.; Chen, J. Design and Experiment on Pull Type of Tassel Fruit Separation for Carrot. Trans. Chin. Soc. Agric. Mach. 2018, 49, 73-79.

6. Maksimov, L.M.; Maksimov, P.L. The separating device of a carrot harvesting combine. Trakt. I Selskokhozya Istvennye Mashiny 2000, 13, 12-13.

7. Ji, W.; Li, J. Analysis and validation for mechanical damage of apple by gripper in harvesting robot based on finite element method. Trans. Chin. Soc. Agric. Eng. 2015, 31, 17-22.

8. Kabas, O.; Celik, H.K.; Ozmerzi, A.; Akinci, I. Drop test simulation of a sample tomato with finite element method. J. Sci. Food Agric. 2008, 88, 1537-1541. [CrossRef]

9. Celik, H.K.; Rennie AE, W.; Akinci, I. Deformation behaviour simulation of an apple under drop case by finite element method. J. Food Eng. 2011, 104, 293-298. [CrossRef]

10. Salarikia, A.; Miraei Ashtiani, S.-H.; Golzarian, M.R.; Mohammadinezhad, H. Finite element analysis of the dynamic behavior of pear under impact loading. Inf. Process. Agric. 2017, 4, 64-77. [CrossRef]

11. Miraei Ashtiani, S.-H.; Sadrnia, H.; Mohammadinezhad, H.; Aghkhani, M.; Khojastehpour, M.; Abbaspour-Fard, M.H. FEM-based simulation of the mechanical behavior of grapefruit under compressive loading. Sci. Hortic. 2019, 245, 39-46. [CrossRef]

12. Kim, G.-W.; Kim, M.-S.; Sagara, Y.; Bae, Y.; Lee, I.-B.; Do, G.-S.; Lee, S.; Kang, S.-W. Determination of the viscoelastic properties of apple flesh under quasi-static compression based on finite element method optimization. Food Sci. Technol. Res. 2008, 14, 221-231. [CrossRef]

13. Gao, Y.; Song, C.; Rao, X.; Ying, Y. Image processing-aided FEA for monitoring dynamic response of potato tubers to impact loading. Comput. Electron. Agric. 2018, 151, 21-30. [CrossRef]

14. ASAE. Compression Test of Food Materials of Convex Shape; ASAE S3684 DEC2000; American Society of Agricultural and Biological Engineers: St. Joseph, MI, USA, 2012.

15. Bentini, M.; Caprara, C.; Martelli, R. Physico-mechanical properties of potato tubers during cold storage. Biosyst. Eng. 2009, 104, 25-32. [CrossRef]

16. Szelag-Sikora, A.; Stankiewicz, A. Fractional Maxwell model of viscoelastic biological materials. Bio. Web Conf. 2018, 10, 1-8.

17. Li, Z.; Miao, F.; Andrews, J. Mechanical Models of Compression and Impact on Fresh Fruits. Compr. Rev. Food Sci. Food Saf. 2017, 16, 1296-1312. [CrossRef] [PubMed]

18. Cao, Y.; Shen, B. ABAQUS 6.14 Chinese Version Finite Element Analysis and Examples; Tsinghua University Press: Beijing, China, 2018.

19. Fu, H.; He, L.; Ma, S.; Karkee, M.; Chen, D.; Zhang, Q.; Wang, S. Bruise Responses of Apple-to-Apple Impact. IFAC Pap. 2016, 49, 347-352. [CrossRef]

20. Celik, H.K. Determination of bruise susceptibility of pears (Ankara variety) to impact load by means of FEM-based explicit dynamics simulation. Postharvest Biol. Technol. 2017, 128, 83-97. [CrossRef]

21. Du, D.; Wang, B.; Wang, J.; Yoa, F.; Hong, X. Prediction of bruise susceptibility of harvested kiwifruit (Actinidia chinensis) using finite element method. Postharvest Biol. Technol. 2019, 152, 36-44. [CrossRef] 